\title{
Los anticuerpos séricos anti-mielina son predictores del desarro- Ilo de esclerosis múltiple (EM) definida
}

Antimyelin antibodies as a predictor of clinically definite multiple sclerosis after a first demyelinating event. Berger $\mathrm{T}$, Rubner $\mathrm{P}$, Schautzer F y col. New Engl J Med. 2003;349:139-45.

\begin{abstract}
Objetivo
Predecir el riesgo de conversión a EM luego de un sindrome desmielinizante aislado (SDA) mediante el dosaje de anticuerpos séricos contra glicoproteína de mielina del oligodendrocito (MOG) y proteína básica de mielina (PBM).
\end{abstract}

Diseño

Estudio de cohorte.

Lugar

Departamentos de Neurología de la Universidad de Innsbruck y del County Hospital de Villach, Austria.

\section{Pacientes}

103 pacientes que presentaron un SDA y que además mostraran hallazgos típicos en la resonancia magnética nuclear (RMN) y bandas oligoclonales en el LCR sugestivos de EM.

\section{Evaluación de factores pronósticos}

Se dosaron al ingreso, anticuerpos contra MOG y PBM (por 2 investigadores separados ciegos al estado neurológico y la RMN). Los pacientes fueron evaluados al inicio y trimestralmente por al menos 12 meses, para la pesquisa de recaídas o progresión de la enfermedad. El período medio de seguimiento fue de 50,9 meses (rango 12-96).El evaluador fue ciego a la serología.

\section{Medición de resultados principales}

Los pacientes fueron divididos en 3 grupos de acuerdo a los hallazgos serológicos. Se calculó el tiempo medio transcurrido a la primer recaída, el porcentaje de pacientes que recayeron y el riesgo de recaer para cada grupo (conversión a EM clínicamente definida).

\section{Resultados principales}

1. Los grupos de pacientes con anticuerpos positivos para uno o ambos antígenos padecieron recaídas más frecuentes y precoces
( $p<0,001$ con respecto a los seronegativos), (tabla 1 ).

2. El riesgo de conversión a EM clínicamente definida fue significativamente mayor para los grupos seropositivos para uno o ambos antígenos.

3. El grupo seropositivo para ambos antígenos mostró un significativo incremento del riesgo versus el grupo seropositivo para un solo antígeno, (tabla 2).

Tabla 1. Pacientes con recaídas y tiempo transcurrido hasta la primer recaída según anticuerpos.

\begin{tabular}{|c|c|c|c|}
\hline & $\begin{array}{c}\text { Negativos para } \\
\text { Anti-MOG y } \\
\text { Anti-PBM (N=39) }\end{array}$ & $\begin{array}{l}\text { Positivos para Anti- } \\
\text { MOG y negativos } \\
\text { para Anti-PBM (N=42) }\end{array}$ & $\begin{array}{c}\text { Positivos para } \\
\text { Anti-MOG y } \\
\text { Anti-PBM (N=22) }\end{array}$ \\
\hline $\begin{array}{l}\text { acientes con } 1 \\
\text { ecaída N (\%) }\end{array}$ & $9(23)$ & 35 (83) ๆ & $21(95) \Uparrow$ \\
\hline $\begin{array}{l}\text { Meses transcurridos } \\
\text { hasta la primer recaída }\end{array}$ & $45,1 \pm 13,7$ & $14,6 \pm 9,6 \mathbb{q}$ & $7,5 \pm 4,4 \rrbracket \S$ \\
\hline
\end{tabular}

I $\mathrm{p}<0,001$ comparación entre pacientes seronegativos para Anti-MOG $y$ Anti-PBM

$\S p=0,002$ comparación entre pacientes positivos para Anti-MOG y negativos para Anti-PBM

Tabla 2. Riesgo para la conversión a EM clínicamente definida según anticuerpos

\begin{tabular}{l|c|c} 
& Hazard ratio $(\mathbf{I C 9 5} \%)^{*}$ & $\mathbf{p}$ \\
\hline - anti MOG, - anti PBM & 1,00 & $<0,001$ \\
\hline + anti MOG, - anti PBM & $31,6(9,5-104,5)$ & $<0,001$ \\
\hline + anti MOG, + anti PBM & $76,5(20,6-284,6)$ & \\
\hline
\end{tabular}

\section{Conclusiones}

En pacientes que padecieron un SDA, el hallazgo de anticuerpos séricos anti-MOG y anti-MBP predeciría en forma individual, rápida, precisa y a bajo costo la conversión a EM clínicamente definida.

Fuente de financiamiento: The Austrian Federal Ministry of Science

\section{Comentario}

Berger y colaboradores ${ }^{1}$ sugieren en este trabajo que pacientes que padecen un SDA y que presentan una respuesta humoral contra MOG y PBM, tienen un riesgo significativamente más alto de desarrollar EM que aquellos seronegativos o que muestran reactividad contra sólo una de las proteínas, proponiendo su uso para predecir el curso de la enfermedad.

Respaldan estos datos el estudio de Vojdani y $\mathrm{col}^{2}$, quienes encontraron que un alto porcentaje de pacientes con EM definida presentan anticuerpos contra PBM, MOG y alfa beta cristalina, sugiriendo que su búsqueda podría utilizarse para el diagnóstico de EM.

Hughes y $\mathrm{col}^{3}$ demostraron que pacientes con EM muestran una respuesta antigénica contra secuencias polipeptídicas (similares a las de PBM y MOG ) de Acinetobacter spp y Pseudomona aeruginosa. Los mismos autores presentaron en la última reunión de la American Neurological Society , ${ }^{2}$ trabajos ${ }^{4}$ que confirman esos hallazgos y que muestran una especificidad del $90 \%$ y una alta sen- sibilidad para estos marcadores en pacientes con EM.

Tomados estos datos en conjunto, sería de esperar, que una vez validados con una población mayor de pacientes con EM y controlados con otras enfermedades de etiología inmune y sujetos sanos, pudiéramos contar con un marcador biológico de la enfermedad (actualmente el diagnóstico está basado en criterios).

Conclusiones del comentador: Si bien queda mucho trabajo por hacer para consolidar estas observaciones y conjeturas, la posibilidad de estratificar el riesgo de progresión de EM es una herramienta de enorme valor ya que el diagnóstico podría hacerse en forma más precoz y precisa -recordemos que la EM se sobrediagnostica en más del $25 \%$ en nuestro medio y el subdiagnóstico podría ser aún mayor-, podría contribuir a seleccionar más racionalmente a los pacientes tratables, la cuantificación de la respuesta humoral podría correlacionarse con la actividad silente de la enfermedad y contribuiría en la búsqueda de claves etiopatogénicas de la enfermedad.

\section{Dr. Edgardo Cristiano [ Subjefe de Neurología Hospital Italiano de Buenos Aires ]}

\section{Referencias}

1.Antimyelin antibodies as a predictor of clinically definite multiple sclerosis after a first demyelinating event. Berger T et al. New Engl J Med. 2003;349:139-45.

2. Antibodies to myelin basic protein, myelin oligodendrocytes peptides, alpha-beta-crystallin, lymphocyte activation and cytokine production in patients with multiple sclerosis. Vojdani A et al.J Intern Med, 2003;254:363-74.

3. Antibody responses to Acinetobacter spp and Pseudomonas aeuruginosa in multiple sclerosis:prospects for diagnosis using the myelin-acinetobacter-neurofilament antibody index. Hughes $L$ et al. Clin Diagn Lab Immunol.2001;8(6):1181-8

4. Presentación oral, American Neurological Society Meeting, 2003.Ann Neurol.2003:54:Suppl 7. 